Canad. Math. Bull. Vol. 15 (1), 1972

\title{
RECENTLY ACCEPTED PAPERS AND NOTES
}

October-December, 1971

\section{RECENTLY ACCEPTED PAPERS}

ADLER, A, Determinateness and the pasch axiom

AL-HussaINI, A. N., On characterizations of conditional expectation

AupETIT, B. H., Theorème de muntz pour les fonctions de plusieurs variables

BACSICH, P. D., An epi-reflector for universal theories

BEUERMAN, D. R., Some functional stable limit theorems

BOZEL, F. and HuSAIN, T., On isomorphisms of locally convex spaces with similar biorthogonal systems

Bryant, J. and Guseman, L. F., Jr., Extensions of contractive mappings and Edelstein's iterative test

Garner, C. W. L., Herzberg, A. M. and Springer, B. G. F., Kiss-precise sequential rotable designs

GuSEMAN, L. F. Jr. and BRYANT, J., Extensions of contractive mappings and Edelstein's iterative test

Hanson, D., On a theorem of Sylvester and Schur

HARdy, G. and Rogers, T., A generalization of a fixed point theorem of Reich

Herzberg, A. M., Garner, C. W. L. and Springer, B. G. F., Kiss-precise sequential rotable designs

HusaIn, T. and Bozel, F., On isomorphisms of locally convex spaces with similar biorthogonal systems

KAUL, S. K., On the irregular sets of a transformation group

MAKan, A., The fitting length of a finite soluble group and the number of conjugacy classes of its maximal metanipotent subgroups

MALIK, M. A., Existence of solutions of abstract differential equations in a local space

MeISEN, J., Pullbacks in regular categories

MelzaK, Z. A., Multiple scalar transport

Millington, H., Nuclear spaces of generalized test functions

Peterson, A. C., On a relation between a theorem of Hartman and a theorem of Sherman

Plummer, M. D. and Wilson, E. L., On cycles and connectivity

Ramachandramurty, P. V. and RaO, M. S., Some comments on quantiles and order statistics

RAO, M. S. and RAmachandramurty, P. V., Some comments on quantiles and order statistics

Rishel, T. W., Images of class $-C$ spaces 
Rogers, T. and HARdy, G., A generalization of a fixed point theorem of Reich

ScotT, K. F. N., On the construction of BIBD with $\lambda=1$

Springer, B. G. F., Herzberg, A. M. and GARner, C. W. L., Kiss-precise sequential rotable designs

SRIVASTAVA, H. M., On the reducibility of appell's function $F_{4}+$

SteIn, S. K., The cardinalities of $A+A$ and $A-A$

WETZEL, J. E., Sectorial covers for curves of constant length

WiLliams, K. S., The kloosterman sum revisited

Wilson, E. L. and Plummer, M. D., On cycles and connectivity in planar graphs

\section{RECENTLY ACCEPTED NOTES}

ARMENDARIZ, E. P., A note on semiprime rings with torsionless injective envelope

Constantin, J., Note sur un problème de maeda

Coppotelli, F., A construction of subequalizers

Eberhart, C., Fugate, J. B. and Mohler, L. Spaces which cannot be written as a countable disjoint union of closed subsets

EnOCHS, E., A note on semihereditary rings

Fugate, J. B., Eberhart, C. and Mohler, L., Spaces which cannot be written as a countable disjoint union of closed subsets

Gupta, H., A partition Theorem of Subbarao

HARLEY, P. W., A countable nowhere first countable hausdorff space

HARUKI, S., A note on a square type functional equation

Houn, C. S., On a structure defined by a tensor field $F$ of type $(1,1)$ satisfying $F^{2}=0$

JEFFRIES, C., Analytic evaluation of certain pontrayagin classes

LORIMER, P., A note on groups of ree type

MiChael, I. M., Finite-dimensional extensions of certain symmetric operators

MiCHLER, G., Example of an injective module which is not nice

Mohler, L., Eberhart, C. and FugATE, J. B., Spaces which cannot be written as a countable disjoint union of closed subsets

MORDELl, L. J., Systems of congruences

SETH, V. and TEWARI, K., On injective near-ring modules

TEUfEL, H., Jr., The stability of solutions of generalized emden-powler equations

TEWARI, K. and SETH, V., On injective near-ring modules

VASILESCU, F.-H., The range sequence of an operator 